\title{
Reseña de Moro Martín, Alfredo, Transformaciones del Quijote en la novela inglesa y alemana del siglo XVIII, Biblioteca Premio Casasayas, Alcalá de Henares, Universidad de Alcalá, 2016, 336 pp. ISBN: 978-84-16599-95-0
}

\section{Sara Santa-Aguilar}

Universidad de Navarra, GRISO

ESPAÑA

ssanta@alumni.unav.es

[Hipogrifo, (issn: 2328-1308), 7.1, 2019, pp. 743-746]

Recibido: 26-11-2018/ Aceptado: 07-12-2018

DOI: http://dx.doi.org/10.13035/H.2019.07.01.57

Transformaciones del Quijote en la novela inglesa y alemana del siglo XVIII, de Alfredo Moro Martín, obra galardonada con el Premio de Investigación Cervantina José María Casasayas en su tercera convocatoria (2015), es sin duda un valioso aporte a los estudios de la recepción del Quijote. Ante una tradición crítica centrada en la influencia del personaje de don Quijote en las literaturas de periodos posteriores, Moro propone un estudio sistemático de las reapropiaciones no sólo del protagonista sino también de lo que denomina, de la mano de Henry Fielding, «la manera de Cervantes». Así, a través de un cuidadoso examen de la obra de Fielding, M.C. Wieland y Walter Scott, lleva a cabo un análisis de la influencia de la novelística cervantina en la gestación de nuevos géneros, como el comic romance (Fielding), el bildungsroman (Wieland), o la novela histórica (Scott), destacando la presencia de elementos como la sátira y parodia de otros géneros literarios y cosmovisiones idealistas, así como su inclusión dialogizada en un universo en principio ajeno a sus lógicas (rasgo que Moro denominará acertadamente 'realismo inclusivo'), además de los diversos juegos con la metaficción y la autoconciencia de la ficcionalidad, que innegablemente remiten a la propuesta del alcalaíno.

El volumen está estructurado en tres capítulos, uno por novelista estudiado, además de un capítulo introductorio y un epílogo. En su introducción Moro brinda un marco teórico sobre el paso del romance a la novela y contextualiza la recepción de Cervantes en Inglaterra y en Alemania a la luz de las transformaciones sociales, científicas y de los debates teóricos y literarios del siglo XVIII. Tal exposición cierra 
poniendo en evidencia el proceso que vertebrará la relación entre los autores estudiados: la recepción del Quijote en las letras inglesas durante la primera mitad del siglo y la posterior popularidad que estas cobran en la Alemania de los años 50, a saber, el proceso que lleva a que Wieland lea a Fielding y así su recepción del Quijote termine siendo influida por la interpretación del inglés.

En el primer capítulo, titulado «Del anti-romance al romance cómico: Henry Fielding y la manera de Cervantes», Moro parte de un estudio de la recepción del Quijote en Gran Bretaña, y pasa a destacar la importancia de Fielding no sólo como eslabón a medio camino entre la interpretación cómica y la interpretación romántica del personaje cervantino, sino como autor que incorpora en su narrativa el proceder novelístico del alcalaíno, algo que Moro propone estudiar en términos del paso del 'quijotismo' al 'cervantismo' (p. 43). Con esta base, da paso al análisis de The History of the Adventures of Joseph Andrews, and his friend, Mr. Abraham Adams (1742).

En su análisis Moro destaca cómo Fielding asimila el modelo de Cervantes en la construcción de una novela que se contrapone a un género anterior, el romance. Así, estudia la construcción de dos tipos de personajes quijotescos: Joseph Andrews y Abraham Adams en su contraste e inadecuación con el mundo cotidiano de la Inglaterra del siglo XVIII. El primero lector e imitador de un romance, la Pamela de Richardson (hermana del personaje en un juego metaficcional típicamente cervantino), en un contexto y situación completamente inadecuados; el segundo, otro personaje libresco que, sin embargo, servirá para mostrar la descomposición de una sociedad en la que un hombre bueno e ingenuo no tiene cabida, con lo que da el primer paso hacia una romantización del personaje quijotesco.

No obstante, la propuesta de Moro, como lo anunciaba en la introducción, trasciende el estudio de las asimilaciones del personaje, y así pasa pronto a un segundo apartado, en el que destaca cómo Fielding, además de incluir el romance como lectura de un personaje quijotesco, termina dando cabida a giros propios de las tramas del romance en su novela, siguiendo una impronta cervantina que remite a las tramas de las historias intercaladas del Quijote, y que en este caso da origen al género del comic romance. Moro cierra con otro agudo análisis en el que destaca cómo Fielding bebe otra lección cervantina más, como lo es el deliberado cuestionamiento de que lo narrado sea una "verdadera historia", a través de un narrador que apunta al carácter de artificio de la construcción literaria y que exige un lector opuesto al lector imitativo que sería Joseph o don Quijote.

Un aspecto que hay que resaltar del volumen de Moro es su orden y simetría. Su estudio del segundo autor, M.C. Wieland, sigue una estructura y metodología paralela a la del capítulo de Fielding. Así, parte de una exposición de la recepción de Cervantes en Alemania, para pasar luego a la recepción de los novelistas ingleses, y con ellos, de la interpretación inglesa del personaje cervantino. Moro destaca la capital importancia de Fielding en la obra de Wieland, y con esta base da paso al análisis de Die Abenteuer des Don Sylvio von Rosalva. 
En su estudio de esta obra, como en el capítulo anterior, Moro inicia con un análisis de la construcción del personaje cervantino, don Sylvio, un ferviente lector de cuentos de hadas, más cercano a don Quijote que el Joseph de Fielding, pues, además de imitar un patrón de comportamiento del modelo libresco, pasa a transformar su entorno según las lógicas de sus lecturas y de una cosmovisión supersticiosa de la realidad, que comparte con otros personajes menos ilustrados y que Wieland se propone ridiculizar. No obstante, como lo destaca el crítico, el novelista alemán hace énfasis en el proceso de 'desquijotización' del personaje, un proceso de corrección epistemológica que da los primeros pasos hacia lo que será el género de la novela de formación o bildungsroman.

Después de esta inicial presentación del personaje, Moro, siguiendo la estructura planteada en el capítulo anterior, estudia también en este caso la herencia del «realismo inclusivo» cervantino, a saber, los giros del tipo de literatura parodiada que Wieland adopta en la construcción de su trama. Concluida esta sección, el crítico da paso también en este caso al estudio de la herencia narratológica de Cervantes, y a los mecanismos que apuntan al carácter explícitamente ficcional de lo narrado. De este modo, pone en evidencia todo el aparato narratorial de Wieland, quien, de la mano de la lección cervantina, construye un nivel extradiegético en el que se dejan oír las voces de editores, traductores y autores ficcionales sobre los cuales se levantan dudas y contradicciones. Además, destaca que el alemán, siguiendo la herencia de Fielding, construye también un narrador que se deja oír remitiendo al carácter de artificio de lo narrado, y que, nuevamente, exige un tipo de lectura opuesta a la de los personajes quijotescos, lectura que se tematizará y se pondrá en marcha dentro de la novela misma, a partir de una absurda historia metaficcional que hace parte del proceso correctivo de don Sylvio.

El tercer capítulo de la obra de Moro da un giro inesperado, pues estudia una novela de principios del XIX, Waverley or 'Tis Sixty Years Since (1814) de Walter Scott, a la que el título del volumen, que se circunscribe al s. XVIII, no le hace justicia y puede excluir de las pesquisas bibliográficas del interesado en el XIX. Si bien el título no cobija este estudio, la elección de esta novela resulta completamente pertinente en el derrotero crítico de Moro, pues permite continuar con el análisis del proceso de 'la recepción de la recepción' que venía estructurando el volumen, pues si Fielding bebe de Cervantes y Wieland bebe de Fielding, con Scott se completará esta 'cadena alimenticia' de la novelística, siendo el autor escocés un admirador de la novela alemana y en particular de M.C. Wieland.

Como en los capítulos anteriores, Moro ofrece un detallado estudio de estos procesos de recepción en Escocia, para llegar a la asimilación de Scott y a su particular interpretación de la locura de don Quijote como un problema de anacronismo. Con esta base, Moro inicia el análisis de Waverley mostrando cómo esta interpretación de la locura quijotesca, junto con las bases del bildungsroman que aporta Wieland, dan paso a un nuevo género literario: la novela histórica, en la que el reto del personaje será abandonar unos ideales heroicos anacrónicos para aceptar los condicionamientos concretos de su presente. 
En definitiva, estamos ante un volumen muy riguroso y bien estructurado. Además de hacer un lúcido aporte con su cuidadoso estudio de la herencia de la novelística cervantina en la gestación de nuevos géneros literarios, Moro invita a ir «del Quijote al Quijote o del mito al método», significativo título de su epílogo, abriendo una fértil línea de investigación. Tal vez por este mismo motivo, por la relevancia que tiene su aporte, lo único objetable sería la prolijidad de datos con la que se detiene en historia de la recepción de la obra cervantina en los contextos de los autores estudiados, pues por momentos estas extensas relaciones hacen que se pierda de vista su propuesta. Así pues, con este único reparo, si es que puede llamarse de este modo, pues, en todo caso, son relaciones cuidadosamente documentadas, es evidente que se trata de un volumen de gran importancia que está llamado a sentar las bases de nuevos enfoques críticos. 